these countries is seen as expert in psychotherapy and in the application of psychotherapeutic principles to psychiatry. This is the way that the profession in this country needs to move if it is not to encourage the devolution of skilled clinical therapeutic practice to other professions.

Grant, S., Holmes, J. \& Watson, J. (1993) Guidelines for psychotherapy training as part of general professional psychiatric training. Psychiatric Bulletin, 17, 695-698.

N. O. T. TEmple, Chairman, Psychotherapy Section, Royal College of Psychiatrists

\section{An indictment of British psychiatry}

Sir: I have just attended a one-day workshop on post traumatic stress disorder, held at the College. The subject of treatment was left until the final hour, when two young research psychologists described a controlled trial they were to undertake. Mine was the only voice in a hall full of consultant psychiatrists expressing an interest in outcomes and the use of brief, effective psychodynamic/behavioural techniques. This void was a frightening indictment of British psychiatry.

Psychiatrists seem to be involving themselves less and less with individual therapy. Team management, committee attendance, assessments and reports are not enough. The consultant should be leading the therapeutic effort, able personally to take on challenging patients. If consultants continue to lead from behind, in a changing world, they may be left behind.

A. SANDERSON, South Bedfordshire Community Health Care Trust, Crombie House, 36 Hockcliffe Street, Leighton Buzzard, LU7 $8 \mathrm{HE}$

\section{Advertisement for part-time posts}

Sir: Could I draw colleagues' attention to the 'Part-Time' section of the British Medical journal classified advertisements? I learnt of this section by chance at an advisory appointments committee and realised that some advertisements may not appear under their speciality heading because they have only been placed in the PartTime section. As an example, in the 13 November 1993 Journal, 13 posts were advertised in the Part-Time section but I could find reference to only five of them in the respective specialty section. I wonder how widely known this practice is and whether it has narrowed the field of applicants for posts.

PETER REDER, Child \& Family Consultation Centre, Wolverton Gardens, London W6 7DQ

\section{Examination blues}

Sir: On receipt of a letter from the College last June, informing me I had failed the second part of the membership exam, I could not fail to notice that the letter was stamped with the 'Defeat Depression' - and the campaign logo. It is reassuring to see the College fostering a healthy sense of humour.

R. A. Laugharne, Princess Alexandra Hospital, Harlow, Essex CM2O 1QX 